\title{
¿Un paso adelante hacia el abismo? Reflexiones sobre Augusto Pinochet y la banalidad del mal
}

A step forward to the abyss? Reflections on Augusto Pinochet and the banality of evil

\author{
Alejandro Varas Alvarado* - Aníbal Carrasco Rodríguez**
}

Resumen: El presente artículo analiza la figura del dictador Augusto Pinochet, a la luz de la categoría de banalidad del mal propuesta por Hannah Arendt, examinando su trayecto desde días previos al golpe de Estado hasta su liderazgo en la Junta Militar. Tomando diversos registros de su vida se propone una triple traición que muestra a Pinochet como un símbolo del alto grado de irracionalidad e irreflexividad que caracterizaron la dictadura cívico-militar, cuyo principal legado es el neoliberalismo que aún pervive en Chile. Se acude a la categoría del pensar en Arendt para develar su ausencia en el dictador y para observar algunas de las implicancias políticas que se desprenden de ello para dicho país.

Palabras clave: Banalidad del mal, pensar, Hannah Arendt, Augusto Pinochet.

Abstract: This paper analyzes the figure of the dictator Augusto Pinochet, through the category of banality of evil proposed by Hannah Arendt, examining his journey from days before the coup d'état to his leadership in the Military Junta. Taking several records of his life, this paper proposes a triple betrayal, which shows Pinochet as a symbol of the enormous irrationality and irreflexivity that characterized the military dictatorship, which main legacy is the neoliberalism that still survives in Chile. This paper takes the category of thinking in Arendt to unveil its absence in the dictator and to observe some of the political implications it has had for our country.

Keywords: Banality of evil, thinking, Hannah Arendt, Augusto Pinochet.

Recibido: 8 septiembre 2018 Aceptado: 29 octubre 2018

\footnotetext{
* Chileno, autor principal. Psicólogo y Magíster en Filosofía. Académico del Departamento de Psicología, Universidad de Playa Ancha de Ciencias de la Educación. Email: alejandro.v.alvarado@gmail.com

** Chileno, autor secundario. Psicólogo y Candidato a Magíster en Literatura, Pontificia Universidad Católica de Valparaíso. Email: anibal_acr@hotmail.com
} 


\title{
Introducción. Pinochet y la (in)diferencia de su consciencia
}

\author{
Como me gustaría andar en las calles, saludando, consolando, ayudando [...] \\ De repetirse la experiencia bubiere deseado, sin embargo, mayor sabiduría \\ Augusto Pinochet ${ }^{1}$ \\ La lucha no nos hizo libres. \\ No bubo DEMOCRACLA AHORA. \\ No bubo JUSTICIA AHORA. \\ El dictador nunca cayó. \\ No bubo PODER POPULAR \\ No bubo HONOR NI GLORLA PARA LOS CAÍDOS. \\ No bubo paredón. \\ Hubo olvido. \\ Hubo perdón. \\ Jaime Pinos $^{2}$
}

La figura de Augusto Pinochet ha sido ampliamente estudiada considerando su rol protagónico durante la dictadura militar de 1973 a 1990, en la medida que impuso en Chile una serie de reformas económicas y políticas ${ }^{3}$, en un contexto de represión y violencia política expresada en variados crímenes de lesa humanidad ${ }^{4}$. No obstante, con menor profundidad y amplitud se ha estudiado la figura del dictador en sí misma, analizando sus discursos y acciones en los momentos previos y posteriores al golpe, desde una mirada filosófica.

En relación con lo anterior, la figura de Pinochet y los crímenes que encabezó, pueden ser analizados bajo el concepto que Arendt, a partir de las elaboraciones de Kant ${ }^{5}$, denominó «mal radical» (Das «Radikal Böse»), modo inicial desde el cual la autora comprende el fenómeno del totalitarismo, el cual posteriormente fue complejizado ${ }^{6}$. Ella, a propósito de los horrores del nazismo en Alemania, retratados en el holocausto judío, afirmó que el problema del mal sería la cuestión fundamental de la postguerra en Europa $^{7}$, declaración de intenciones que dio contenido a su producción intelectual a lo largo de varias décadas. En Los origenes del totalitarismo, Arendt plantea que se trata de

un mal absolutamente incastigable e imperdonable que ya no puede ser comprendido ni explicado por los motivos malignos del interés propio, la sordidez, el resentimiento, el ansia de poder y la cobardía. Por eso la ira no puede vengar; el amor no puede soportar; la amistad no puede perdonar.

\footnotetext{
1 Pinochet, A. 2004, Mensaje a mis compatriotas para ser difundido a mi fallecimiento. p. 2.

2 Pinos, J. 2010. Almanaque. Lanzallamas Libros. p. 44.

3 Véase Ahumada et al. (1990); Cavallo, Salazar y Sepúlveda (1998), Novaro y Palermo (2003), Katz (2006), Llanos (2014) y Huneeus (2016), entre otros.

4 Véase Verdugo (1989), Chile (1991), Padilla (1995) y Kornbluh (1999), entre otros.

${ }^{5}$ Kant señala "podremos, pues, llamar a esta propensión una propensión natural al mal, y, puesto que, sin embargo, ha de ser siempre de suyo culpable, podremos llamarla a ella misma un mal radical innato [radical del latín raíz] (pero no por ello menos contraído por nosotros mismos) en la naturaleza humana”. Kant, Immanuel (1986). La religión dentro de los límites de la mera razón. Trad. de F. Martínez Marzoa, Madrid, Alianza Editorial. Pág. 42.

${ }_{6}^{6}$ Véase Birulés, F. (comp.), Hannah Arendt: el orgullo del pensar. Barcelona: Editorial Gedisa, 2000.

7 Arendt, Hannah. "Nightmare and Flight". Arendt, H. Essays in understanding 1930-1954. Nueva York: Harcourt Brace, 1994.
} 
[...]. Hay sólo algo que parece discernible: podemos decir que el mal radical ha emergido en relación con un sistema en el que todos los hombres se han tornado igualmente superfluos ${ }^{8}$.

Sin duda, esta definición puede ser un buen marco desde el cual comprender los crímenes de la dictadura en Chile, la cual se inicia con el golpe de Estado, y adquiere contenido a través de las distintas operaciones militares, que tienen por finalidad perseguir y asesinar a los opositores al régimen: Plan $Z$ (1973), Caravana de la muerte (1973), Operación Cóndor (1974-90), Operación Colombo (1975), y Operación Albania (1987). La desaparición forzada de más de mil doscientas personas, la retención en campos de detención de cientos de miles de individuos, en donde se aplicaron diversas formas de tortura a alrededor de veintiocho mil personas y fueron ejecutadas unas dos mil doscientas, nos habla de un mal extremo nunca antes visto en Chile, no sólo en lo cuantitativo, sino también en lo cualitativo. Un mal radical mediante el cual los sujetos — siguiendo a Arendt— "ya no pertenecen a comunidad alguna [...], no existe ley alguna para ellos" 9 . El mal radical, tal como fue aplicado en la dictadura chilena, siguió un método similar al sistema totalitario nazi, el cual, siguiendo a Arendt, se presenta en tres momentos que se necesitan entre sí, los que a su vez van cimentando el camino para la dominación total: el asesinato de la persona jurídica en el hombre, la destrucción de la persona moral y, finalmente, la destrucción de lo humano en los individuos, a través de la tortura y el asesinato sistemático ${ }^{10}$.

¿Cómo es que este horror de tal magnitud acontece en nuestra historia? ¿En qué medida dichos crímenes son explicables a partir de la subjetividad de quienes tomaron tales decisiones? ¿'Tiene sentido hablar de un mal en los militares? ¿Un «mal radical» en Augusto Pinochet? Lo que sí es seguro es la necesidad de hablar de una maldad más allá de los convencionales esquemas teológicos, morales o psicopatológicos ${ }^{11}$. Esta exploración de la subjetividad del dictador ha sido considerada por autores como Soto ${ }^{12}$, Uribe ${ }^{13}$, Witker ${ }^{14}$, Karmy ${ }^{15}$ y Timmermann ${ }^{16}$, destacando la interpretación que éste último hace al plantear la fórmula del 'factor Pinochet', entendida aquella

\footnotetext{
8 Arendt, Hannah. Los orígenes del totalitarismo. Madrid: Taurus Ediciones, 1974. Versión española de Guillermo Solana, pp. 556557.

${ }_{9}$ Ibid., 246.

10 Arendt, op. cit. Ante esta interpretación habría que considerar la advertencia que nos hace el historiador Miguel Valderrama: "no lejos de este reproche se escucha otro que nos advierte severamente de los peligros de convertir el golpe de Estado del 73 en "nuestro pequeño Auschwitz". (...). El problema con estas posiciones supuestamente afirmativas de la vida y del porvenir es que (...) expresan el deseo de superación propio de un tiempo de duelo llamado normal. Contra estas posiciones habría que insistir en la necesidad de la remarca, en lo que Patricio Marchant denominó el comentario de la catástrofe como catástrofe nacional” (Larrea, Felipe; Sepúlveda, Néstor (2013). «Historiografía y desaparición. Conversación con Miguel Valderrama por Felipe Larrea y Néstor Sepúlveda». Escrituras Aneneconómicas. Revista de Pensamiento Contemporáneo, (4), p. 9).

${ }^{11}$ Esta pregunta va en sintonía con lo afirmado por Timmermann: "Un síntoma actual de lo mencionado es el hecho de demonizar a Pinochet, de tratarlo como una "pesadilla" que pasó por nuestro país, razonamiento que es usado por no pocos como el elemento fundamental para comprender cuánto aconteció en el régimen militar, sin pretender discutir ni superar las razones que existieron para que ello ocurriera y ocultando un hecho esencial en este sentido: que el régimen militar contó con el respaldo "de una considerable parte de la población" y, en especial, de una élite cívico-militar" (Timmermann, "El factor Pinochet. Élites y democracia", Revista Temas Psicológicos, 10, 2005, p. 224).

12 Soto Gamboa, Ángel. "Gonzalo Vial, Pinochet. La Biografía”, Historia (Santiago), 36, 2003, pp. 450-458.

13 Véase Uribe, Armando. El Fantasma de la sinrazón y el secreto de la poesía. Santiago de Chile: Be-uve-dráis Editores, 2001.

14 Véase Witker, Iván. Homo Loquax Pinochet: Imágenes y estereotipos en la prensa chilena. Universum, Talca, v. 20, n. 1, p. 204-224, 2005. En este texto se presenta un análisis de las imágenes en prensa chilena respecto a Pinochet. Es interesante notar cómo los estereotipos respecto a esta nefasta figura transitan por diversos constructos, los cuales se encuentran en consonancia con el espectro político al que responden estos medios, en este sentido, la figura de Pinochet se muestra carente de contenido en sí misma.

15 Véase Karmy, Rodrigo, “¿Qué es 'Pinochet’? (Violencia, derecho y vida)”, Nuevo Mundo Mundos Nuevos [En ligne], Questions du temps présent, mis en ligne le 16 mars 2007, consulté le 21 novembre 2018. URL: http://journals.openedition.org/nuevomundo/3822; DOI: 10.4000/nuevomundo.3822.

16 Véase Timmermann, "El factor...”, op. cit., pp. 219-232; y Timmermann, Freddy, "Psicohistoria y poder. Reflexiones desde el factor Pinochet", Boletin de historia y geografía, 20, 2006, pp. 205-218.
} 
como la tendencia de un individuo de escasa cultura introspectiva a mantener la estabilidad en el control del espacio de poder que posee, ejerciendo la fuerza por sobre el poder mayormente aunque no exclusivamente, convirtiendo en objetos de manipulación los contextos teóricos históricos y las realidades humanas presentes en las coyunturas en que está inserto, por medio de una "ideología formal" flexible; desarrollando una conducta instrumental en que los medios son los fines, y el fin es el poder por sí mismo; en una acción constante que abarca también sus microcoyunturas cotidianas, siempre inserto en una tensión psíquica de competencia extrema por estos espacios de poder en que no se descarta la anulación del rival, de cualquier tipo que ésta sea, tendiendo a operar como un "superviviente"17.

Si bien nuestro análisis coincide con lo planteado por el autor, nuestro trabajo profundiza y distingue en aquello que podría llamarse 'escasez de introspección', con el fin de comprender justamente aquel estilo controlador, instrumental e ideológicamente flexible. Para ahondar en ello haremos un breve recorrido de la participación de Pinochet en la conjura del golpe, desde el Tanquetazo, ocurrido tres meses antes del golpe, llegando hasta la destitución del general Leigh en 1978. Consideramos que observar este proceso puede hacer emerger preguntas interesantes sobre el mal, en concordancia con los planteamientos de la pensadora judío-alemana, y desde lo que la figura del dictador nos muestra. Y esto debido a que lo que realmente se esfuerza por esconder Pinochet no es su historial de crímenes, sino, más bien, la verdadera historia de cómo él inicia este camino y que ha intentado camuflar y tergiversar en sus diferentes escritos ${ }^{18}$.

\section{Una triple traición}

El viernes 29 de junio de 1973, los tanques del Regimiento Blindado No 2 liderado por el Teniente Coronel Roberto Souper, emprendieron camino hacia La Moneda y el Ministerio de Defensa, y, al llegar, abrieron fuego. Esta fue la primera rebelión militar en contra del Gobierno de la Unidad Popular. El Comandante en Jefe del Ejército, el General Prats, salió a la calle encabezando la Escuela de Suboficiales, con el fin de enfrentarlos. Desde el norte, vino en apoyo el Regimiento Buin, bajo la dirección de Pinochet, Jefe del Estado Mayor del Ejército a la fecha, quien era leal al gobierno ${ }^{19}$. Cuando Prats y Pinochet se encuentran a las afueras de La Moneda, éstos se abrazan, frente a todas las tropas ${ }^{20}$. Para el mediodía la situación fue controlada. Dos meses después, a finales de agosto, Prats renuncia a la comandancia, asumiendo en su lugar Pinochet. Este último le escribe, el 7 de septiembre, una emotiva carta en la que declara su "invariable afecto hacia su persona" y sus "sentimientos de sincera amistad"21. Sólo un año después, Prats es asesinado por la DINA en Buenos Aires. Cuando a Pinochet le preguntaron en una ocasión si era jefe directo de la DINA, él respondió: "No me acuerdo, pero no es cierto. No es cierto, y si fuera cierto, no me acuerdo"'22.

La Cofradía, y la casa de Lo Curro fueron desde 1970 e inicios del '73, respectivamente, las dos instancias desde las que se planeó el golpe. Augusto Pinochet no participó presencialmente en estas instancias, ni tampoco tuvo incidencia en la planificación sediciosa por más que él mismo insista en

\footnotetext{
17 Timmermann, "El factor...”, op. cit., p. 221.

18 Para una panorámica de los diversos escritos de Pinochet, véase la bibliografía. En el presente trabajo nos focalizamos en textos de prensa e intervenciones fuera de las obras escritas por el dictador. Lo anterior, en la medida que la autoría y calidad de los textos ya han sido cuestionados (véase González, Mónica. La conjura: los mily un días del golpe. Santiago de Chile: Ediciones B, 2000; y Jocelyn-Holt, Alfredo. El Chile perplejo: del avanzar sin transar al transar sin parar. Santiago de Chile: Editorial Planeta, 1998). ${ }^{19}$ Como plantea Timmermann: "La presencia de la doctrina Prats en la vida de Pinochet lo convierte en un general no golpista, hasta la última semana de agosto de 1973" (Timmermann, "Psicohistoria...", op. cit., p. 209).

20 González, M., op. cit., p. 176.

21 Ibid., 289-290

22 “El interrogatorio del ministro Víctor Montiglio a Pinochet”. La nación. 22 nov. 2005. País.
} 
aquello23. Al contrario, como plantea Alejandra Matus: "Pinochet, siempre esquivo a las definiciones, se aproximaba, por su conducta de militar no deliberante (...) a las ideas constitucionalistas de Schneider" 24 . Así también en una entrevista concedida en México antes del golpe, Pinochet declara: "El Ejército chileno es institucional y respeta y apoya al Presidente, su jefe, sin considerar sus ideas políticas" 25 . Fue inicialmente el general Arellano, recién el 8 de septiembre, quien informó a Pinochet de que el golpe se realizaría sólo tres días después, con o sin él: "su reacción fue una mezcla de sorpresa y molestia. Al tomar consciencia de que sólo se requería su adhesión a una decisión ya tomada, pareció abrumado"26. Según lo que plantea Mónica González: "Pinochet habló poco esa noche. Estaba preocupado: tenía que tomar una decisión [...]. En un momento me dijo textualmente: ‘¡Yo no soy marxista, mierda!' y golpeó el brazo del sillón en el cual estaba sentado [...]"27.

Al día siguiente, Leigh visitó a Pinochet en su casa, y le preguntó “¿Qué piensas hacer tú? Porque lo que es nosotros, no damos más. Creo que estamos en un punto en que si no actuamos el país se va al caos", a lo que Pinochet respondió vacilante "¿Tú has pensado que esto nos puede costar la vida a nosotros y a muchos más?" 28 . Según el testimonio de Leigh sobre lo sucedido ese día, él comenta: "Por supuesto - le repliqué-, pero aquí no queda otra cosa que jugarse. Él siguió especulando y vacilando" 29. Un poco más tarde, llegó a la casa el almirante Huidobro, quien trajo consigo una carta escrita por Merino, la cual confirmaba por escrito lo que Stark y Leigh ya habían manifestado. En esta se le solicita a él y a Leigh colocar sus firmas; Pinochet declara dubitante: "yo no tengo planes, no puedo traer tropas, no puedo hacer ninguna cosa [...], ante cualquier movimiento del Ejército [están] encima Carabineros e Investigaciones" 30 ; y agrega: "si esto se filtra, puede sernos de graves consecuencias" 31 . El relato de Merino confirma la versión de Leigh: "Yo firmé de inmediato. Pinochet vaciló un poco buscando un timbre que quería colocar al lado de su firma y que no encontraba nunca"32; hasta que el comandante de la aviación exclamó: “Decídase mi general, firme!”33. Finalmente, Pinochet estampó su firma y con esto selló su participación.

La inserción de Pinochet en la conjura tiene un carácter similar al proceso de implementación de nuestra actual economía neoliberal. Merino, siendo quien se encargó de esta iniciativa al comienzo, planteó: "La intención inicial fue devolver todas las empresas que tenían dueño, pero enseguida, tanto Pinochet como Leigh, manifestaron su deseo de mantener una economía controlada por el Estado. Por eso al principio fue muy difícil que entrara el Plan Ladrillo. ¿Y qué es "El Ladrillo"?, preguntaban"34.

\footnotetext{
${ }^{23}$ La Cofradía Nántica del Pacífico Austral era una sociedad secreta que sirvió como fachada para la preparación del golpe; sus fundadores fueron el Comandante en Jefe de la Armada, José Toribio Merino; los vicealmirantes Patricio Carvajal y Arturo Troncoso; los ex oficiales navales Roberto Kelly y Hernán Cubillos; Agustín Edwards, dueño de El Mercurio; Sergio de Castro, redactor de "El Ladrillo"; entre otros. Por otro lado, los generales que más frecuentemente asistieron a la casa del abogado Jorge Gamboa, ubicada en Lo Curro 9122, barrio de la clase alta santiaguina, fueron, por parte del Ejército: Sergio Arellano, Washington Carrasco, Javier Palacios, Hernán Brady, César Benavides y Ernesto Baeza; por parte de la Aviación: Gustavo Leigh, Nicanor Díaz Estrada, Francisco Herrera Latoja; por parte de Carabineros: Arturo Yovane y César Mendoza; y por parte de la Armada, nuevamente los almirantes Merino y Carvajal, sumándose a estos: Ismael Huerta, Sergio Huidobro y Hugo Castro. Véase González (2000), González (2002), Rojas, Uribe, Rojas, Largo, Ropert y Espinoza (2003), Biblioteca Nacional de Chile (2013), entre otros.

${ }_{24}$ Matus, Alejandra. Doña Lucia; la biografía no autorizada. Ediciones B Chile, Santiago de Chile, 2016, p. 92.

25 Ibid., p. 96.

${ }^{6}$ Verdugo, Patricia. Interferencia Secreta. Santiago de Chile: Editorial Sudamericana Chilena, 1998, pp. 15-16.

27 González, M., op. cit., p. 305.

28 Verdugo, op. cit., p. 22.

${ }^{29}$ González, M., op. cit., pp. 306-307.

30 Ibid., p. 310.

31 Verdugo, op. cit., p. 24.

32 González, M. op. cit., p. 310.

33 Verdugo, op. cit., p. 24.

34 González, M., op. cit., p. 430.
} 
Lo que pasó el día 11 es conocido por todos. Mas, desde ese mismo día Pinochet comenzó a posicionarse como líder político, en disputa con los protagonistas de la conjura. Durante el bombardeo a La Moneda se le comunica radialmente a Pinochet el contenido de una declaración a emitirse ese mismo día. El general desea agregar por su propia cuenta unas últimas líneas a ésta:

Otra cosa... [...] recalcar: que las Fuerzas Armadas no están contra el pueblo, sino que están contra la hambruna que estaba sembrando el gobierno marxista del señor Allende... contra las colas que rodean... que rodean a todas las calles de Santiago... [...] contra el hambre, contra la pobreza, contra la miseria, contra el sectarismo a que nos estaba llevando el señor Allende, mientras él satisfacía con fiestas y parrandas en la casa... ${ }^{35}$

Como plantea Verdugo, mientras los militares escuchan sorprendidos, los socios de la conjura comienzan a darse por notificados. Este hecho constituyó la antesala de otros dos: su autoproclamación como Presidente de la República y la expulsión de Leigh de la Junta Militar. En un inicio la presidencia de la Junta tendría un carácter rotativo, sin embargo, Pinochet quiso quedarse con todo el poder y Leigh no escondió su malestar como auténtico ideólogo de la conjura, haciéndole saber su rechazo a la decisión. El general de la FACH comenta: "a Pinochet le vino un ataque de furia, dio un golpetazo a la mesa, quebró el cristal, se rompió un poco la mano y sangró. Ahí, Merino y Mendoza me dijeron que yo debía firmar, porque si no la Junta se iba a dividir. Firmé"36. El 24 de julio de 1978, Pinochet declaró a Leigh imposibilitado para ejercer sus funciones, siendo reemplazado por el general Matthei.

Relatados estos hechos, varias cosas saltan a la vista y plantean algunas interrogantes que nos gustaría resumir en tres: Primero: ¿Qué implica esta triple traición de Pinochet? ${ }^{37}$ Comúnmente se destaca cómo traicionó la confianza de Allende en los días anteriores al golpe, sin embargo ¿cómo explicar a su vez la expulsión de Leigh y el asesinato de Prats? ¿Cuál es el porqué de la traición a camaradas de su propia institución? ${ }^{38} \mathrm{Y}$ es que Allende, Prats y Leigh representan tres posicionamientos políticos e ideológicos claramente diferenciables: el marxismo-leninismo, la doctrina Schneider ${ }^{39}$, y la derecha conservadora, respectivamente. ¿Qué motiva a deshacerse de todos y cada uno de estos bloques políticos? Segundo: ¿Qué implica esta brutal transformación tan repentina? El mismo Carlos Prats afirma y se pregunta lo siguiente, en una carta dirigida a Moy de Tohá, esposa de José Tohá: "En cuanto a la conducta de Pinochet, puedo decirte que su traición no tiene parangón en la historia de Chile. ¿Cómo puede entenderse su trayectoria bonachona y dúctil entre marzo y septiembre de 1973 (...)?" ${ }^{40}$. En sólo tres días Pinochet pasa de aceptar a regañadientes un plan ajeno a liderarlo como si fuese ya el jefe máximo de la nación, un acérrimo antimarxista y el salvador de Chile. Sólo en unos pocos años pasa de identificarse con un estatismo, a defender, encabezar y materializar el salvaje libre mercado de los Chicago Boys. Y en sólo unos pocos años,

\footnotetext{
35 Verdugo, op. cit., p. 87

36 "El general Leigh: pensamiento y sentimiento 48 horas después de ser destituido en 1978”. La Segunda. 30 sep. 1999 , p. 8.

37 Pensamos que esta pregunta da luces sobre la siguiente afirmación planteada por Karmy: "todo el "espectro" político está originariamente "amarrado", "por" y "a" Pinochet: la derecha, comprometida con Pinochet hasta el último peso, la Concertación hasta la última ley y la izquierda -lo que queda de ella- hasta el último desaparecido" (Karmy, Rodrigo, “Qué es "Pinochet”? (Violencia, derecho y vida)", Nuevo Mundo Mundos Nuevos [En ligne], Questions du temps présent, mis en ligne le 16 mars 2007, consulté le 21 novembre 2018. URL: http://journals.openedition.org/nuevomundo/3822; DOI: 10.4000/nuevomundo.3822). 38 Pregunta similar se plantea Timmermann con respecto a la 'deslealtad' del dictador, al realizar una periodización que coincide en general con los hitos expuestos en este trabajo, a saber, la fidelidad a Prats al inicio y la expulsión de Leigh al final. No obstante, la respuesta ofrecida por el autor incursiona en los grados de libertad o sometimiento que Pinochet tuvo en las coyunturas históricas específicas (Véase Timmermann, "Psicohistoria...", op. cit., p. 209).

${ }^{39}$ Doctrina derivada del pensamiento de René Schneider Chereau (1913 - 1970), comandante en jefe del ejército nombrado por Eduardo Frei Montalva, quien transmitió la idea, según la cual, el ejército debía seguir un estricto respeto a las leyes y la constitución, manteniendo su función absolutamente apolítica. Esta posición fue luego popularizada por el gobierno de la Unidad Popular como la <<Doctrina Schneider >>. El 22 de octubre de 1970 el comandante René Schneider sufrió un atentado que lo dejó hospitalizado, falleciendo 3 días después del suceso.

40 Matus, op. cit., p. 149.
} 
después de toda una vida de obediencia a los militares y a la patria, traiciona a su Comandante en Jefe, a quien alguna vez incluso trató de "hermano" 41 , y a Leigh, con quien asaltó La Moneda el 11. ¿Cómo podemos comprender esta serie de cambios tan abruptos y antagónicos? Tercero: ¿Pueden estos dos hechos -la triple traición ideológica y el brutal y repentino cambio- decirnos algo sobre el mal radical que caracterizó a la dictadura de Augusto Pinochet? 42

\section{La banalidad de Augusto Pinochet}

La noción de mal en Arendt, luego de Eichmann en Jerusalén, tomó un giro importante que tiene sentido abordar acá. Mientras en un primer periodo el énfasis estuvo puesto en el «mal radical», caracterizado por la intención de volver superfluos a los seres humanos mediante los crímenes de los totalitarismos; en un segundo periodo, esta noción se articula a sus reflexiones relativas al pensar, y es allí cuando aparece el polémico concepto de «banalidad del mal». Arendt entiende por esta noción

\begin{abstract}
al fenómeno de los actos criminales, cometidos a gran escala, que no podían ser imputados a ninguna particularidad de maldad, patología o convicción ideológica del agente, cuya única nota distintiva personal era quizás una extraordinaria superficialidad. [...] el agente no era un monstruo ni un demonio, y la única característica específica que se podía detectar [...] no era estupidez, sino una curiosa y absolutamente auténtica incapacidad para pensar. [...] no tenía ni la más mínima dificultad en aceptar un conjunto enteramente distinto de reglas. Sabía que lo que antes consideraba su deber, ahora era definido como un crimen, y aceptó este nuevo código de juicio como si no fuera más que otra regla de lengua distinta ${ }^{43}$.
\end{abstract}

Vemos entonces que la conceptualización de Arendt respecto del mal sufre modificaciones: el mal ya no sería radical, sino más bien superficial, como el genocidio que puede provocar una bacteria, la que nada sabe de dioses o intenciones. En ese sentido, ella llega a señalar que el mal nunca es radical, que a lo más es «extremo», que sólo la reflexión es profunda y puede ser radical, porque se dirige a los fundamentos. Cuando el pensamiento toma como objeto de reflexión al mal, el primero se frustra porque no encuentra nada ${ }^{44}$. De lo extremadamente superfluo a lo que la condición humana puede llegar a ser, Arendt ha transitado a comprender el mal desde quienes lo cometen, desde la falta de reflexividad en aquellos. ¿Podemos hablar de una "incapacidad" para pensar en Augusto Pinochet?

En primer lugar, no encontramos estupidez. Al contrario, hay una astucia en Pinochet que Jocelyn-Holt reconoce: "lo que más sorprende es su extraordinaria habilidad para hacer de las derrotas su victoria, tanto de los otros como de las propias" 45 , habilidad que no es fruto de la suerte ni mera coincidencia. Una inteligencia que, junto a ciertos rasgos perversos, dejaron entrever la consciencia que el dictador tenía respecto de sus crímenes y lo poco que le interesaban las implicancias de reconocerlos frente a las cámaras.

De esto último, tenemos frases icónicas. Éstas emergieron ante preguntas hechas por periodistas, las que fueron transmitidas vía mass media a toda la sociedad chilena. Por ejemplo, cuando le preguntan sobre por qué acostumbraba a ocupar lentes oscuros, responde: "la mentira se descubre por los ojos, yo muchas veces mentía"46; o "si aquí hay en este momento trece millones de chilenos, póngale que hubiera

\footnotetext{
41 Jocelyn-Holt, op. cit., p. 167.

42 De todos modos, debemos reconocer que finalmente Pinochet fue fiel a la ideología neoliberal, posibilitando las condiciones para su implementación en Chile. No obstante, hablamos de traición en el sentido de que Pinochet no es fiel al modelo de forma constante, clara y explícita, sino al contrario, se orienta a éste de forma equívoca, repentina y contradictoria, desplazando incluso a quien lo lidera en sus inicios.

43 Arendt, Hannah. De la bistoria a la acción, Barcelona: Editorial Paidós, 1995, p. 109.

44 Véase Birulés, F., op. cit.

45 Jocelyn-Holt, op. cit., p. 165

46 "La historia de Pinochet en algunas de sus más célebres frases", El Mercurio, p. 74.7 ene. 2010. Web. 8 oct. 2018.
} 
doce, de doce, dos mil no es nada" 47 . Si examinamos las diversas frases ya célebres del dictador, nos percatamos que, en el fondo, como señala Arendt, se genera una suerte de frustración en nosotros, porque no hay una postura ni ideas que se puedan someter a crítica, análisis, etc. En realidad, los dichos de Pinochet surgen como si estuviera improvisando una respuesta, trivializando lo que sabe, con un sentido común rígido, que silencia un posible trasfondo ${ }^{48}$. Algo similar ocurre con Eichmman, quien según Arendt tenía una "incapacidad casi total para considerar cualquier cosa desde el punto de vista de su interlocutor" ${ }^{49}$. Como veremos más adelante, aquella capacidad se relaciona con el pensamiento; el otro, quien encarna la diferencia, no aparece, y por ello hay una ausencia de reflexión. Desde allí se hace viable que un sujeto habiendo cometido crímenes tan atroces, pueda vivir sin culpa aparente, como si las personas hubiesen sido enterradas y exterminadas tanto real como imaginariamente.

Por otro lado, en Pinochet hay una soberbia pseudointelectual acomplejada, condensada en Geopolitica, plagio de las clases de Gregorio Rodríguez, su profesor en la Academia de Guerra ${ }^{50}$; libro en el que podemos encontrar frases como "hidrografía marítima del mar" 51 o, que el boliviano posee una "escasa cultura [que] lo mantiene en un estado de estancamiento con respecto a los demás países sudamericanos" 52 . Reemplazar a Schneider y a Prats implicaba estar a la altura de ellos, empresa imposible desde un inicio siendo que ambos generales reconocían la pobreza reflexiva de Pinochet. Schneider calificó a Pinochet como "un general de poco vuelo intelectual" ${ }_{33}$ y Prats planteó respecto a éste que "en su personalidad (...) se conjugan admirablemente una gran pequeñez mental con una gran dosis de perversidad espiritual" 54 . En coherencia con aquello, se advierte en Pinochet una misticidad delirante 55 , cuando asegura "Yo los estoy viendo desde arriba, porque Dios me puso ahí, la Providencia, el destino" 56 , identificándose con Cristo al afirmar "soy el general de los pobres" ${ }^{57}$. Esta astucia, habilidad, inteligencia o consciencia ¿Qué relación posee con el pensar? Aunque dejáramos de lado la categoría de la estupidez en Pinochet, esto no implica una actividad del pensamiento. Ocurre que conocer no es lo mismo que pensar.

Arendt retoma de Kant la diferencia establecida entre entendimiento y razón para construir su propia teoría sobre la facultad de juzgar. En Crítica de la razón pura, el filósofo plantea:

[...] hemos definido el entendimiento diciendo que es la facultad de las reglas; ahora distinguimos la razón del entendimiento denominándola la facultad de los principios [...]. Por consiguiente, yo denominaría conocimiento por principios aquel en que conozco por conceptos lo particular en lo general ${ }^{58}$.

\footnotetext{
${ }^{47}$ Salinas, Luis A. The London Clinic. Santiago de Chile: Editorial Lom, 1999, p. 112.

48 Véase el documental Pinochet y sus tres generales (2004), del director José María Berzosa. Frente a la pregunta por el significado político de la visita que realizó a la base militar antártica chilena, Pinochet responde: "La significación política, en el sentido de llegar a la tierra de Chile, yo he recorrido todo Chile y me faltaba recorrer esta parte no más".

49 Arendt, Hannah. Eichmann en Jerusalén. Un estudio sobre la banalidad del mal. Barcelona: Editorial Lumen, 2003, p. 33.

50 Véase Peña, Juan Cristóbal. La secreta vida literaria de Augusto Pinochet. Santiago de Chile: Editorial Debate, 2013.

51 Pinochet, Augusto. Geopolitica. Santiago de Chile: Editorial Andrés Bello, 1974, p. 90.

52 Peña, op. cit., p. 72. Para sorpresa de Gregorio Rodríguez, Pinochet solicitó a éste prologar aquel libro plagiado, a lo que el primero se negó sin dar explicaciones.

53 Ibid., p. 33

54 Ídem.

${ }^{55}$ En coherencia con lo que plantea Timmermann: "Se ocultó ante el peligro y lo desterró, legitimándose en función de un héroe construido por los intérpretes de Dios que lo rodeaban o por el mito que las élites le construyen, no por uno que tuviera como base una historia concreta, real." (Timmermann, "El factor...", op. cit., p. 226).

56 Salinas, Luis A. The London Clinic. Santiago de Chile: Editorial Lom, 1999, p. 19.

57 Azócar, Pablo. “Augusto Pinochet: rasgos psíquicos del general”. APSI 173, mar. 1986, año 10, pp. 8-11. Web. 8 oct. 2018 , p. 11; Salinas, op. cit., p. 25.

58 Kant, Immanuel. Crítica de la razón pura. Vol. 2, Dialéctica trascendental y metodología trascendental. Buenos Aires: Editorial Losada, 1960. Traducción de Rovira Armengol, pp. 49-50.
} 
Como afirma Wellmer, esto es lo que lleva posteriormente a Kant a plantear el «juicio reflexivo» como aquel que "nos permite encontrar un universal o una norma universal bajo la cual un caso particular determinado puede ser subsumido" 59 ; en donde la máxima es reflexionar sobre el propio juicio desde un punto de vista universal. Siguiendo este esquema elemental, para Arendt sólo el pensar permite juzgar entre el bien y el mal; el mal extremo, como lo mostró el totalitarismo alemán y la dictadura chilena, no responde a ningún fenómeno visto anteriormente, por lo tanto, el juzgar aquí no es algo que se base en el conocimiento que poseemos acerca de él, sino más bien de los principios que compartimos como sociedad. Este juicio es un ejercicio que no obedece a reglas, ya que justamente el mal extremo rompe las reglas que se tienen hasta el momento para juzgar; aparece de modo auxiliar la facultad de imaginar, y con ello el juicio es, a la vez, un ejercicio de creación de nuevas reglas que tienen carácter de principios.

La perspicacia de Pinochet no nos habla directamente de un pensar como facultad, al contrario; su triple traición y su repentina transformación dan cuenta de una indiferente obediencia a reglas, cualesquiera estas sean dependiendo de la ocasión, ya que no hay principios que guíen al agente respecto al sentido profundo que poseen aquellas. Como relata uno de sus exescoltas: "a mi general le gustaba aprender. 'Yo soy como un perro', me decía. 'No hablo, pero entiendo todo"' 60 . Este 'entender' es un conocer, un conocer que no admite un pensar que se traduzca en un 'hablar' auténtico. Se impone el entendimiento por sobre la razón, la obediencia por sobre la autonomía. El repentino antimarxismo de Pinochet no pareciera ser un producto de una fuerte convicción ideológica, sino, más bien, el efecto de la inexistencia de una ideología propia, lo que lo obliga a adherirse a la conjura del golpe. Sin embargo, tal adherencia no es auténtica, ya que nuevamente no hay incomodidad alguna en asesinar a Prats y expulsar a Leigh. No importa si se trata de estatismo o de neoliberalismo, Pinochet no duda en aceptar cualquiera de estos modelos mientras le permitan seguir avanzando, seguir obedeciendo a una especie de mandato. Pinochet no es una víctima, es culpable de todos sus crímenes, pero dicha culpabilidad no pareciera tener que ver con motivos que lo posicionan políticamente en un bloque en particular, más bien es capaz de eliminar todos los bloques políticos que le impidan lograr la posición que desea.

Arendt en El pensar y las reflexiones morales utiliza la figura de Sócrates para definir el pensar, haciendo mención a sus tres sobrenombres: el "tábano", el "torpedo", y la "comadrona".

Sócrates es un tábano: sabe cómo aguijonear a los ciudadanos que, sin él, continuarían durmiendo para el resto de sus vidas, a menos que alguien más viniera a despertarlos de nuevo. ¿'Y para qué los aguijoneaba? Para pensar, para que examinaran sus asuntos [...]. Sócrates es una comadrona [...], la función propia de la comadrona griega de decidir acerca de si la criatura estaba más o menos adaptada para vivir o [...] era un mero $<<$ huevo estéril $>>[\ldots]$. El torpedo, a primera vista, parece lo opuesto al tábano; paraliza allí donde el tábano aguijonea $[\ldots]^{61}$.

Estas tres metáforas hablan de tres dimensiones respecto al pensar desde Arendt. Primero, cuando pensamos, dejamos de obedecer y comenzamos a cuestionar las reglas que obedecemos; aquello supone una vivencia de dolor o sufrimiento ya que, cuestionar las reglas propias implica cuestionarse a uno mismo, es decir, significa evidenciar las propias contradicciones que en nuestra vida cotidiana intentamos esquivar. Cuando alguien nos hace pensar, o nos obliga a hacerlo, el pensamiento se entromete en nosotros como un malestar que ataca constantemente y del cual sabemos que no podremos librarnos de manera fácil. Segundo, el pensar no tiene ninguna función servil, ni útil. Al contrario, el pensar es destructivo, en vez de sustentar o asimilar reglas, normas, instituciones, sociedades, es sumamente peligroso debido a cómo propicia a socavarlas, derruirlas, exterminarlas. Y el pensar es autodestructivo, es un dudar de uno mismo constantemente que no deja nada tras de sí, sólo coloca en movimiento lo que antes estaba quieto sin llegar a ningún lugar predefinido. Y tercero, al pensar

59 Birulés, op. cit., p. 266.

${ }^{60}$ Matus, op. cit., pp. 206-207.

${ }^{61}$ Arendt, De la historia..., op. cit., pp. 123-124. 
paralizamos nuestro quehacer cotidiano, colocamos en pausa a la realidad y con ella a nosotros mismos, e ingresamos en una temporalidad diferente. Tal como el telar que teje y desteje Penélope, el pensar es una acción destructiva, pero que posibilita la emergencia de lo nuevo, abre espacio para la creación, tiene una cierta finalidad, sólo que ésta es indeterminada y no inmediata, trascendiendo a sí misma, "el proceso del pensar no produce cosas tangibles [...] La concreción que se da al escribir algo, al pintar una imagen, o al componer una pieza de música, etc., es lo que hace realmente del pensamiento una realidad [...]"62. Así ocurre, si continuamos con la metáfora, con Penélope ya que su telar le permite engañar a los hombres que desean tomar el puesto de Odiseo, posibilitando el ansiado retorno de su marido, rey de Ítaca.

Jocelyn-Holt describe a Pinochet de un modo consonante con lo anterior al plantear que él "nunca cede o transa. Él es, paradójicamente, la máxima encarnación del avanzar sin transar" ${ }^{3}$, y podemos traducir transar por pensar. Pareciera ser que Pinochet nunca cuestionó ingresar a la conjura, la aceptó de forma irreflexiva; detener su avanzar implicaba una paralización de la realidad y de sí mismo, no había tiempo para decidir si ingresar o no ingresar a la conjura, no hay plazos para considerar posibilidades alternativas, es el todo o nada. Como ordena Pinochet al momento de atacar La Moneda: "No podemos aparecer con debilidad de carácter, aceptándole plazos y parlamento a esta gente porque... ¡no podemos nosotros aceptar plazos ni parlamentos, que significa diálogo, significa debilidad!”64; diálogo circular que expresa por un lado la superficialidad y por otro la incapacidad para someterse al dolor del diálogo, con debilidad al aguijón del transar. Como comenta en una entrevista, Pinochet prefiere secretamente no someterse a dicho dolor, prefiere el conformismo antes que el sufrimiento del pensar y decidir:

- ¿Qué le recomendaría a los chilenos como pauta de conducta? [pregunta la entrevistadora]

—El término medio. Ni mucho ni poco. Siempre en los términos medios está lo justo (...)”. ${ }^{65}$

Hay una cercanía que no podemos dejar de mencionar entre Pinochet y Chance Gardiner, personaje principal de la novela Desde el jardin ${ }^{66}$ del autor polaco Jerzy Kosinski. Chance vivió toda su vida sin salir de su hogar, pasando gran parte de su tiempo frente al televisor y dedicado a cultivar un pequeño jardín en el patio trasero. Su vida se moviliza entre esos dos polos: televisor-jardín. Hasta que un día quien lo cuidaba fallece. Frente al desamparo Chance se ve forzado a salir de la casa en la que había vivido, ya no podía seguir viviendo ahí debido a la muerte del anciano que lo cuidaba. Casi de casualidad encontró la puerta que daba al exterior. Al poco andar es atropellado por un auto lujoso de donde descendió una mujer que le prestó auxilio y ofreció llevarlo a la clínica. Caen en simpatía y junto a ella poco a poco comienza a conocer la "realidad" y con fortuna y una gran cuota de azar entra en contacto con personas con una situación acomodada, las que paulatinamente lo empujan hacia las capas poderosas de la sociedad: empresarios, políticos, prensa, etc. Casi por azar, sin proyecto alguno, termina siendo aclamado por políticos y empresarios, con frases sacadas de su escasa experiencia entre lo que podía aprender de la televisión y lo que veía en su jardín a diario. Frente a una pregunta en torno a la situación políticaeconómica Chance responde: "En todo jardín hay una época de crecimiento. Existen la primavera y el verano, pero también el otoño y el invierno, a los que suceden nuevamente la primavera y el otoño.

${ }^{6}$ Ibid., p. 102.

${ }^{63}$ Jocelyn-Holt, op. cit., p. 167. Frase acuñada en 1971 por el secretario general (1971-79), diputado (1961-65) y senador (196573) del Partido Socialista Carlos Altamirano Orrego (1922-), frente a la frase moderada del partido comunista "consolidar lo avanzado".

64 Verdugo, op. cit., p. 121.

${ }_{65}$ Matus, op. cit., p. 150. "Poco después de realizar esta entrevista, la periodista Malú Sierra fue secuestrada. Mujeres vestidas como voluntarias de CEMA se presentaron (...) y la invitaron a integrarse al voluntariado. Ella se negó amablemente y, momentos más tarde, al salir del trabajo, se encontró en la calle con las mismas mujeres. Estaban acompañadas por agentes de la DINA que la subieron a la fuerza a un vehículo y la trasladaron a Villa Grimaldi. (...) Malú Sierra estuvo desaparecida por un día y en los interrogatorios sus captores le preguntaban majaderamente, entre otras cosas, por esa entrevista" (Matus, op. cit., p. 151).

${ }^{66}$ Cuyo título original es "Being there" que traducido al castellano se podría entender como "Estando alli". 
Mientras no se hayan seccionado las raíces todo está bien y seguirá estando bien.” 67 . ¿No son acaso equiparables en estilo y contenido? Con frases como aquellas Chance deja impresionado o al menos satisfecho a quienes iba conociendo en su escalada, siendo citado en periódicos, atrayendo hacia sí miradas desde todos los sectores.

- Señor Gardiner ¿cuándo cree usted que el Gobierno dejará de calificar de venenosos a los subproductos industriales? Estuve de acuerdo en que se prohibiera el uso del DDT puesto que el DDT es un veneno y no hay ningún problema en encontrar sustitutos químicos. Pero es muy distinto que, por ejemplo, tengamos que dejar de refinar el petróleo para calefacción porque, digamos, no nos gustan los productos de la descomposición del querosene - Chance se quedó mirándolo en silencio-. Francamente, creo que hay una diferencia fundamental entre las cenizas del petróleo y los polvos insecticidas. ¡No hace falta ser muy inteligente para darse cuenta de semejante cosa, por Dios!

-Conozco las cenizas y conozco los insecticidas — dijo Chance-. Sé que los dos son perjudiciales para el desarrollo de un jardín ${ }^{68}$.

La banalidad de Chance es similar a la de Pinochet, ambos son movidos por la contingencia, ambos carecen de espontaneidad. Las mismas frases repetidas una y otra vez hasta el cansancio, en ellos no hay proyecto y sin embargo transitan muy bien el espacio que crean las miradas pasivas. ¿No es acaso la misma contingencia la que lleva al general a tomar el poder de la junta y luego a detentar el poder por 17 años? Tal como Chance maneja su acervo doméstico, Pinochet se aferra a la lógica de un lenguaje castrense. ¿Por qué se aferra a él en toda entrevista, en todo comentario? Quizá porque ese lenguaje, hecho para disminuir imprecisiones, altamente pragmático, funcional y rígido, mantenía a raya la reflexión y la nimiedad del general. Como señala Armando Uribe respecto al lenguaje de la poesía y su diferencia fundamental con el lenguaje de la ley:

"Ellos no mandan, prohíben y permiten sino por su gran poder como palabras con vida. En cambio las palabras de la ley persuaden y obligan, mandan, prohíben o permiten sólo porque la ley tiene imperium una potencia de coerción que dispone de la fuerza de poder, e impone desde afuera de las normas las sanciones" 69 . Uno de los pilares de las organizaciones militares es que existen "tan solo cuando la orden tiene un valor siempre idéntico y constante"70.

Cuando esta barrera cae aparece la contradicción, el sin sentido: "De cada diez chilenos, uno tendrá automóvil, de cada cinco, uno tendrá televisor y de cada siete, uno tendrá teléfono" 71 . Así como no hay tiempo para detenerse, menos lo hay para regresar atrás, es decir para recordar. Así lo dejan ver varias frases del dictador al respecto: "La única cosa que queda señores contertulios es jolvidar! Y se olvida no con un proceso que se abre nuevamente y que se vuelve a abrir" 72 ; "Siempre he dicho que esto debe terminar, dar vuelta la hoja y seguir adelante" "73. Pinochet es consciente del peligro destructivo y autodestructivo del pensar y es por eso que, así como lo prohíbe para los demás, lo prohíbe para sí mismo: "Los estudiantes van a la Universidad a estudiar, no a pensar... y si aún les quedan energías, para eso está el deporte" 74 . La esterilidad del pensar no está permitida para nadie.

${ }^{67}$ Kosinski, Jerzy. Desde el jardín. Buenos Aires: Javier Vergara Editor, 1975. Traducción de Nelly Cacici, p. 72.

68 Ibid., p. 41.

${ }^{69}$ Uribe, Armando. El Fantasma de la sinrazón. Santiago de Chile: Imprenta Salesianos, 2001, p.29

${ }^{70}$ Canetti, Elías. Masa y poder. Barcelona: Muchnik Editores, 1981, p. 243.

71 "Tras asegurarse el poder con el referéndum Pinochet anuncia la formación de un comité cívico-militar". ABC Sevilla. 13 de septiembre de 1980. Internacional: 17.

72 Amnistía Internacional. La transición en la encrucijada: las violaciones de derechos bumanos durante el gobierno de Pinochet siguen siendo el problema esencial, 1996.

73 El Mercurio, op. cit., p. 2010.

${ }^{74}$ Salinas, op. cit., p. 26. 
A nuestro parecer, el modo más interesante de definir la banalidad del mal está en la diferencia que Arendt establece entre consciencia y pensamiento. La autora plantea que "la consciencia no es lo mismo que el pensar; pero sin ella el pensamiento sería imposible. Lo que el pensamiento en su proceso actualiza es la diferencia que se da en la consciencia" 75 . ¿De qué se trata esta diferencia que se da en la consciencia? Es admitir que en el hecho de ser conscientes de nosotros mismos existe un acto recursivo, en el cual nosotros nos observamos a nosotros mismos y nos sabemos haciéndolo. Como demuestran las perversas declaraciones del tipo “¡Pero qué economía más grande!” (a propósito del hallazgo de dos cadáveres en una misma tumba $)^{76}$, vemos que esta consciencia existe, más el pensamiento lo que hace es actualizar. Y es dicha actualización la que Pinochet no está dispuesto a aceptar, esa conversación interior consigo mismo sobre su propia diferencia. Adjuntamos un extracto de entrevista hecha en 2003 a Pinochet en sus últimos días.

Entrevistadora: -Usted sabe muy bien que algunos lo aman y otros lo odian. Unos consideran que usted fue el salvador de Chile y otros dicen que fue el dictador que violó derechos humanos. Dígame ¿Cómo usted se ve a usted mismo?

Pinochet:-Que difícil la pregunta, como se va a ver uno, o sea como ángel.

Entrevistadora: -Siempre como ángel...

Pinochet: -Pero creo yo que... reflexionando... y meditando, soy bueno, soy un hombre que no tengo odio en el corazón.

Entrevistadora: $-\mathrm{Ni}$ resentimientos

Pinochet: -Tampoco. Tengo bondad, cuando lo puedo hacer, hago algo en favor de cualquiera. ${ }^{77}$

Si bien, ciertamente destaca enormemente el hecho de llamarse así mismo un ángel —lo cual es coherente con su misticidad delirante- nos interesa mucho más relevar la frase que antecede a tal declaración: "qué difícil la pregunta, cómo se va a ver uno". Más adelante en la misma entrevista se le pregunta sobre los conceptos errados que puede haber sobre su persona, Pinochet responde: "No sé, nunca me he examinado como persona". Es esta dificultad la que nos da pistas sobre cómo Pinochet vive esa actualización de la diferencia de su consciencia, es decir, ese pensar(se), o esa facultad de juzgar(se). Y la respuesta a esa pregunta es superficial en la medida en que no ahonda en su "odio en el corazón"; aquel ejercicio puede ser tan autodestructivo que es necesaria la anteposición de una imagen delirante de sí mismo, imagen estática, inmóvil, sin actualización. Nos parece que, desde otra vía, las conclusiones de Uribe sobre la figura de Pinochet son acertadas, y las traemos a colación como modo de terminar provisoriamente estas reflexiones.

[...] desde el comienzo la conducta del señor Pinochet (y de otros alrededor suyo como reflejo de la suya, pues la suya concentró todas las conductas) ha sido de una alta irracionalidad [...]. Es el estallido de volcán, la erupción del inconsciente, de la irracionalidad chilena. De modo que esto tiene historia, y nunca el país, ¡nunca!, desde cuando tiene nombre en el siglo XVI, había visto un fenómeno de irracionalidad colectiva concretada en una persona como la que vemos ahora en Chile carnalizada en el señor Pinochet ${ }^{78}$.

\section{A modo de epílogo}

En ningún caso creemos que Pinochet pueda ser idéntico a Eichmann, aunque su tránsito desde la Escuela Militar hasta llegar a ser Presidente de la Junta Militar y luego ser dictador por 17 años, no es

\footnotetext{
75 Arendt, De la bistoria..., op. cit., p. 133

${ }^{76}$ Salinas, op. cit., p. 35.

77 Pinochet, Augusto. "Última entrevista al General Augusto Pinochet Ugarte”. Entr. María Elvira. nov. 2003.

78 Uribe, Armando y Miguel Vicuña. El accidente Pinochet. Santiago de Chile: Editorial Sudamericana Chilena, 1999, pp. 71-73.
} 
tan distante de la carrera fortuita que llevó Eichmann a participar de la creación y consolidación del régimen nazi: Eichmann, en ese contexto, movido por su ansia de ser un buen funcionario, escaló sistemáticamente hasta lograr estar a cargo del transporte de miles de judíos a los campos de concentración. La forma en que se desenvolvieron ambos en sus respectivas carreras militares, sumado a ciertos rasgos psíquicos, nos llevan a afirmar que hay una similitud, no en su contenido, pero sí en su lógica de "carecer de un proyecto".

Una de las cuestiones que diferencia a Eichmann de Pinochet es el proceso judicial sin término que tuvo este último, el juicio quedó abierto, dejando a gran parte de la población desamparada en términos legales y con una sensación de impunidad frente a las atrocidades cometidas. El espectro de Pinochet sigue deambulando y tiene su correlato en las familias que esperan justicia por las atrocidades cometidas en dictadura; Pinochet es un símbolo de la precaria justicia Chilena y del desamparo vivido por el pueblo, por quienes no participamos de las altas cúpulas del poder económico y político en aquel entonces. A pesar del juicio inconcluso han brotado voces de personas que participaron de aquellos actos, confesando su responsabilidad y la de otros en los crímenes de lesa humanidad. El resultado del juicio en ambos casos, el de Londres para Pinochet y el de Jerusalén para Eichmann, marca una diferencia importante ya que el segundo concluyó sometiendo a juicio y condenando a muerte a Eichmann; en cambio Pinochet continuó en el ejercicio del poder hasta 1998 como Comandante en Jefe del Ejército, con prácticas coercitivas frente a los juicios que se levantaban contra él y su familia, para terminar sus días ostentando el cargo Senador Vitalicio. Pinochet murió junto a nosotros, extendió su vida, no se escondió, ni armó otra vida en el extranjero (como lo hizo Eichmann). Gozó de toda una capa de la población que lo siguió apoyando y celebrando hasta el día de su muerte impune. Si bien hay similitudes con Eichmann, Pinochet está lejos de parecerse a Hitler.

Utilizar la noción de «mal extremo» como modo de comprender los crímenes en dictadura, y la de «banalidad del mal» para comprender la figura del autor en cuestión, creemos que es un ejercicio no acabado, inexacto, provisorio, por construir. Nos interesan más las preguntas que se formulan en este texto que las respuestas a las que de manera dificultosa hemos podido dar solución momentánea.

Efectivamente las violaciones a los Derechos Humanos en dictadura no se reducen a los actos de Pinochet, al contrario, es el conjunto de diversos actores pertenecientes a las Fuerzas Armadas y a la derecha conservadora los que articularon y dieron expresión a este periodo histórico. En este sentido, no nos interesa tanto dar cuenta de la responsabilidad de Pinochet, la cual es evidente y no se necesita este tipo de análisis para responder a tal cuestión, más bien, nos interesa ahondar en la figura de Pinochet para comprender las implicancias, en la historia de un pueblo, de la incapacidad de pensar. En esta lectura de lo banal que puede llegar a ser el mal, cabe recordar que el fantasma de la sinrazón deambula aún en Chile y, cómo no, si vivimos en el legado político-económico que se inició en la dictadura. Ésta última fue la que dio forma a una democracia incompleta, en la que como vimos y continuamos viendo, no hay justicia frente a los delitos contra el género humano ${ }^{79}$, y en donde, en definitiva, se instauró el ensayo mundial del sistema neoliberal. Este legado tiene su símbolo más claro en la permanencia de la Constitución ilegítima de $1980^{80}$.

El efecto del neoliberalismo implantado por irreflexión ha traído, de manera consecuente, más irreflexión en Chile. Y es que, el interés mercantil, utilitario, e inmediatista del quehacer cotidiano no nos permite detenernos a examinar la banalidad de nuestras vidas, en la que evitamos a toda costa el dolor de la duda, ya que evidentemente es más fácil mantener sólidos nuestros principios. Hay una frase de Augusto Pinochet que llama profundamente nuestra atención tanto por su incongruencia como por su resonancia con lo planteado por Arendt: "Ayer estábamos al borde del abismo, hoy hemos dado un paso

\footnotetext{
79 Arendt, Eichmann..., op. cit.

80 Garretón, Manuel y Roberto Garretón. "La democracia incompleta en Chile: La realidad tras los rankings internacionales". Revista de ciencia política, 2010, vol. 30, n 1, pp. 115 - 148.
} 
hacia adelante"81. Nuevamente, queremos ir más allá del evidente sinsentido, ya que consideramos que el supuesto paso hacia adelante ha sido posible en la medida en que ese abismo se ha intentado clausurar. El abismo es la profunda escisión que en Chile se actualizó durante el gobierno de la Unidad Popular, es la diferencia de la consciencia chilena puesta en movimiento. La dictadura lo que hizo fue rellenar con tierra ese abismo y crear una llanura, es decir, creó una superficie, la cual es escarbada desde abajo por las consciencias aún dolidas, por los crímenes contra la humanidad que aún son cubiertos por un velo. Esta superficie fue creada a partir de todo el cúmulo de reformas en la dictadura, las cuales, estando aún vigentes, sustentan una impunidad que no siempre indica ausencia de derecho, sino las múltiples trabas que obstruyen el ejercicio correcto de la justicia y la distorsión del cuerpo legal. La impunidad termina deformando la confianza y el sentido de lo que es la justicia para los ciudadanos ${ }^{82}$.

Claramente, las diferencias socioeconómicas, políticas y culturales no se borran simplemente con la imposición política de un olvido, idiotización, y rutinización colectivas, sin embargo, creemos que sí podríamos decir que el paso adelante no nos hizo caer a un abismo sin fondo, más bien nos hizo estrellarnos con esta falta de profundidad vital en la que estamos envueltos, una incapacidad para pensarnos de manera colectiva. ¿Hemos dado un paso adelante hacia el abismo? Hacia el abismo no, sí hacia la banalidad. Creemos que tomar consciencia del abismo que existe en Chile, visibilizarlo, hacerlo público, puede ser la facultad de juzgarnos, la actividad de pensarnos como comunidad. Creemos que podemos ciertamente "avanzar" en la medida en que regresamos, colocarnos en ese borde para observar con claridad el abismo en el que vivimos realmente, el cual se extiende por la historia de Sudamérica y el mundo.

Queda pendiente una examinación en profundidad de la psicología de Pinochet, como un personaje que nos interpela en nuestra construcción identitaria como habitantes de Chile. Algo de perturbador tiene la imagen del "tatita", con su voz serena y sus largos silencios. Aquel aspecto ominoso, en palabras de Freud, tiene relación con algo otrora familiar que se ha vuelto extraño ¿Qué es eso que ha quedado deformado bajo la barrera de la represión y que reaparece? Creemos que eso que retorna, ese material sin elaborar, es la historia de cómo se ha construido este país que ha sido golpeado, saqueado, masacrado sistemáticamente, dejando al pueblo y su tejido social destruido ¿No estará tras el rostro de Pinochet la mirada de Valdivia, la de O’Higgins, Portales, etc? Creemos que ese horror está anclado a las grandes matanzas, a las grandes tomas de conciencia del pueblo que han sido aplastadas, a una serie de personajes de nuestra historia que han encarnado diversas atrocidades y que han personificado las cumbres de la banalidad, frente a ellas aún perdura el olvido, creemos que no hemos sido capaces aún de volver sobre nuestra historia con una mirada crítica. Mientras eso no ocurra el rostro y las palabras de Pinochet nos seguirán pareciendo perturbadoras y pretéritamente inquietantes.

Una transformación radical de la sociedad, hacia la superación de las relaciones de opresión en las que vivimos actualmente es posible en la medida en que un proyecto emancipatorio apunte a combatir la banalidad de forma permanente. Hacer frente a la irreflexión, a la privación de las herramientas y los recursos para pensarnos colectivamente, quizá son grandes puntos gravitatorios para construir una nueva historia en Chile. Quizá las izquierdas tienen precisamente ese punto como suelo o como punto articulador para plantear la lucha: el hecho de que los seres humanos no debieran por ningún motivo volverse superfluos, prescindibles e innecesarios al punto de ser materia de exterminio. La necesidad de reflexionar constantemente sobre nuestra histórica banalidad para que de ella no emerja un nuevo y viejo mal radical.

\footnotetext{
81 Bruschtein, Luis. "Las frases del tirano”. Página 12. 12 abr. 2006.

82 Cabrera, Luisa. "Efectos de la impunidad en el sentido de justicia". Psicología política, 2001, n 23, pp. 37-58.
} 


\section{BIBLIOGRAFÍA}

ABC Sevilla. "Tras asegurarse el poder con el referéndum Pinochet anuncia la formación de un comité cívico-militar". 13 de septiembre de 1980. Internacional: 17. Web. 8 oct. 2018. $<\underline{\text { http://hemeroteca.sevilla.abc.es/nav/Navigate.exe/hemeroteca/sevilla/abc.sevilla/1980/0 }}$ 9/13/017.html>

Ahumada, Eugenio; Egaña, Javier Luis; Góngora, Augusto; Quesney, Carmen; Saball, Gustavo; y Villalobos, Gustavo. Chile: La Memoria Probibida. Las violaciones a los derechos bumanos 1973-1983. Pehuén Editores. Colección Testimonios. 3 tomos. Santiago de Chile, mayo de 1990.

Amnistía Internacional. La transición en la encrucijada: las violaciones de derechos humanos durante el gobierno de Pinochet siguen siendo el problema esencial, 1996. Web. 8 oct. 2018. $<\underline{\text { https://www.amnesty.org/es/documents/amr22/001/1996/es/> }}$

Arendt, Hannah. "Nightmare and Flight". Arendt, H. Essays in understanding 1930-1954. Nueva York: Harcourt Brace, 1994.

Arendt, Hannah. De la historia a la acción, Barcelona: Editorial Paidós, 1995.

Arendt, Hannah. Eichmann en Jerusalén. Un estudio sobre la banalidad del mal. Barcelona: Editorial Lumen, 2003.

Arendt, Hannah. Los orígenes del totalitarismo. Madrid: Taurus Ediciones, 1974. Versión española de Guillermo Solana.

Azócar, Pablo. “Augusto Pinochet: rasgos psíquicos del general”. APSI 173, mar. 1986, año 10, pp. 8-11. Web. 8 oct. 2018. < http://www.saladehistoria.com/Revistas/Apsi/pdf/APSI-173.pdf>

Biblioteca Nacional de Chile. 1-11 de septiembre de 1973, 2013. Web. 8 oct. 2018. $<$ http:/ / www.memoriachilena.cl/602/articles-124662_recurso_2.pdf $>$

Birulés, F. (comp.), Hannah Arendt: el orgullo del pensar. Barcelona: Editorial Gedisa, 2000.

Bruschtein, Luis. "Las frases del tirano". Página 12. 12 abr. 2006. Web. 8 oct. 2018. $<$ http://www.pagina12.com.ar/diario/elmundo/subnotas/77208-24917-2006-12-04.html>

Cabrera, Luisa. "Efectos de la impunidad en el sentido de justicia". Psicología política, 2001, n 23, pp. 3758.

Canetti, Elías. Masa y poder. Barcelona: Muchnik Editores, 1981.

Cavallo, Ascanio; Salazar, Manuel; y Sepúlveda Óscar. La historia oculta del régimen militar, Santiago de Chile, Editorial Sudamericana, 1998.

Correa, Raquel y Elizabeth Subercaseaux. Ego Sum Pinochet. Santiago de Chile: Zig Zag, 1989.

Chile. Comisión Nacional de Verdad, \& Reconciliación. (1991). Informe Rettig: informe de la Comisión Nacional de Verdad y Reconciliación (Vol. 1). La Nación.

El Mercurio. "La historia de Pinochet en algunas de sus más célebres frases", 7 ene. 2010. Web. 8 oct. 2018. $\quad<\underline{\text { http://www.emol.com/noticias/nacional/2006/12/10/238587/la-historia-de- }}$ pinochet-en-algunas-de-sus-mas-celebres-frases.html>

Garretón, Manuel y Roberto Garretón. "La democracia incompleta en Chile: La realidad tras los rankings internacionales". Revista de ciencia política, 2010, vol. 30, n 1, pp. 115 - 148.

González, Ignacio. El día en que murió Allende. Santiago de Chile: Editorial Lom, 2002.

González, Mónica. La conjura: los mil y un días del golpe. Santiago de Chile: Ediciones B, 2000.

Huneeus, Carlos. El régimen de Pinochet. Penguin Random House Grupo Editorial Chile, 2016.

Jocelyn-Holt, Alfredo. El Chile perplejo: del avanzar sin transar al transar sin parar. Santiago de Chile: Editorial Planeta, 1998.

Kant, Immanuel. Crítica de la razón pura. Vol. 2, Dialéctica trascendental y metodología trascendental. Buenos Aires: Editorial Losada, 1960. Traducción de Rovira Armengol.

Kant, Immanuel. La religión dentro de los límites de la mera razón. Trad. de F. Martínez Marzoa, Madrid, Alianza Editorial, 1986. 
Karmy, Rodrigo, “¿Qué es 'Pinochet’? (Violencia, derecho y vida)”, Nuevo Mundo Mundos Nuevos [En ligne], Questions du temps présent, mis en ligne le 16 mars 2007, consulté le 21 novembre 2018. URL: http://journals.openedition.org/nuevomundo/3822; DOI: 10.4000/nuevomundo.3822.

Katz, Claudel. Chile Bajo Pinochet, Editorial Anagrama, Santiago de Chile, 2006.

Kornbluh, Peter. Pinochet Los Archivos Secretos, Editorial Crítica, Santiago de Chile, 1999

Kosinski, Jerzy. Desde el jardín. Buenos Aires: Javier Vergara Editor, 1975. Traducción de Nelly Cacici.

La nación. "El interrogatorio del ministro Víctor Montiglio a Pinochet". 22 nov. 2005. País. Web. 8 oct. 2018. $\quad<$ http://www.lanacion.cl/el-interrogatorio-del-ministro-victor-montiglio-apinochet/noticias/2005-11-22/214215.html>

La Segunda. "El general Leigh: pensamiento y sentimiento 48 horas después de ser destituido en 1978". 30 sep. 1999 , p. 8.

Llanos Reyes, Claudio. Del experimento socialista a la experiencia neoliberal. Reflexiones Históricas sobre Chile actual. Estudos Ibero-Americanos, vol. 40, núm. 2, julio-diciembre, 2014, pp. 202 223.

Matus, Alejandra. Doña Lucia; la biografía no autorizada. Ediciones B Chile, Santiago de Chile, 2016.

Novaro, Marcos y Vicente Palermo, La dictadura militar. 1976/1983: del golpe de Estado a la restauración democrática. Editorial Paidós. Buenos Aires, 2003

Padilla, Elías, La memoria y el olvido. Detenidos desaparecidos en Chile, Ediciones Orígenes, Santiago, 1995.

Peña, Juan Cristóbal. La secreta vida literaria de Augusto Pinochet. Santiago de Chile: Editorial Debate, 2013.

Pinochet, Augusto. Sintesis geográfica de Chile, Argentina, Bolivia y Perú. Santiago de Chile: Instituto Geográfico Militar, 1953.

Pinochet, Augusto. Servicio de la información. Quito: s/n, 1956.

Pinochet, Augusto. Sintesis geográfica de Chile. Santiago: Instituto Geográfico Militar, 1965.

Pinochet, Augusto. Geografía militar. Santiago de Chile: Instituto Geográfico Militar, 1967.

Pinochet, Augusto. Guerra del Pacifico. 1879. Primeras operaciones terrestres. Memorial del Ejército de Chile. $\mathrm{N}^{\circ} 365$ y 366. Biblioteca del Oficial, (volumen XLVI). Santiago de Chile: Estado Mayor General del Ejército/Publicaciones Militares, 1972.

Pinochet, Augusto. Geopolítica. Santiago de Chile: Editorial Andrés Bello, 1974.

Pinochet, Augusto. El día decisivo, Santiago de Chile: Editorial Andrés Bello, 1979.

Pinochet, Augusto. Ensayo sobre un estudio preliminar de una geopolítica de Chile en el año 1965. Memorial del Ejército de Chile, Biblioteca del Oficial, (volumen. LXII), Santiago de Chile: Estado Mayor General del Ejército/Publicaciones Militares, 1979.

Pinochet, Augusto. Política, politiquería y demagogia. Santiago de Chile: Editorial Renacimiento, 1983.

Pinochet, Augusto. Pinochet: patria y democracia. Santiago de Chile: Editorial Andrés Bello, 1985.

Pinochet, Augusto. Transición y consolidación democrática, 1984-1989, Santiago de Chile: Centro de Estudios Sociopolíticos, 1989.

Pinochet, Augusto. Camino recorrido: biografía de un soldado. Santiago de Chile: s.n., 1990.

Pinochet, Augusto. Discursos principales, 1995/1998. Augusto Pinochet Ugarte. Capitán General. Principales discursos del Comandante en Jefe del Ejército. 1995.

Pinochet, Augusto. Augusto Pinochet: diálogos con su historia. Entr. María Eugenia Oyarzún. Santiago de Chile: Editorial Sudamericana Chilena, 1999.

Pinochet, Augusto. "Última entrevista al General Augusto Pinochet Ugarte". Entr. María Elvira. nov. 2003. Web. 8 oct. 2018. <https://www.youtube.com/watch?v=nKeLy5HmUZ0>

Pinochet, Augusto. Mensaje a mis compatriotas para ser difundido a mi fallecimiento, 2004. Web. 8 oct. 2018. $<$ http://www.elmundo.es/elmundo/2006/12/24/internacional/1166976334.html>

Pinos, Jaime. Almanaque. Santiago de Chile: Lanzallamas libros, 2010.

Rojas, Paz, Viviana Uribe, María E. Rojas, Iris Largo, Isabel Ropert y Víctor Espinoza. Páginas en blanco; el 11 de septiembre en La Moneda. Parte II, 11 de septiembre, Golpe militar en Chile, 2003. Web. 8 oct. 2018. < http://www.derechos.org/nizkor/chile/libros/blanco/cap10.html> 
Salinas, Luis A. The London Clinic. Santiago de Chile: Editorial Lom, 1999.

Soto Gamboa, Ángel. "Gonzalo Vial, Pinochet. La Biografía”, Historia (Santiago), 36, 2003, pp. 450-458.

Timmermann, Freddy. "El Factor Pinochet. Elites y Democracia". Revista Temas Sociológicos. 2005. n 10, pp. 219-232.

Timmermann, Freddy, "Psicohistoria y poder. Reflexiones desde el factor Pinochet", Boletin de bistoria y geografia, 20, 2006, pp. 205-218

Uribe, Armando y Miguel Vicuña. El accidente Pinochet. Santiago de Chile: Editorial Sudamericana Chilena, 1999.

Uribe, Armando. El fantasma de la sinrazón y el Secreto de la poesía. Santiago de Chile: Be-uve-dráis Editores, 2001.

Verdugo, Patricia, Los zarpazos del puma, CESOC, Santiago de Chile, 1989.

Verdugo, Patricia. Interferencia secreta. Santiago de Chile: Editorial Sudamericana Chilena, 1998.

Witker, Iván. "Homo Loquax Pinochet. Imágenes y estereotipos en la prensa chilena”. Universum, 1, 2005, pp. 204-224. 